\title{
An Analysis of Campus Culture, Mental Health, and Drinking at Three Canadian Universities
}

\author{
Laura Henderson \\ University of Calgary \\ Kara Thompson \\ St. Frances Xavier University \\ Amanda Hudson \\ Dalhousie University \\ Keith Dobson \\ University of Calgary \\ Shu-Ping Chen \\ University of Alberta \\ Sherry Stewart \\ Dalhousie University
}

\begin{abstract}
Although many individual risk factors have been identified for student mental health problems and alcohol misuse, there is a relative paucity of research that examines how variables, such as campus environment, contribute to students' experiences of these problems. This study examined a series of perceived campus environment factors (e.g., feeling valued, feeling they fit in, believing faculty care about them,
\end{abstract}

Laura Henderson, Department of Psychology, University of Calgary, Calgary, Alberta; Kara Thompson, Department of Psychology, St. Frances Xavier University, Antigonish, Nova Scotia; Amanda Hudson, Department of Psychology, Dalhousie University, Halifax, Nova Scotia; Keith Dobson, Department of Psychology, University of Calgary, Calgary, Alberta; Shu-Ping Chen, Department of Public Health Sciences, Queen's University, Kingston, Ontario; Sherry Stewart, Department of Psychology, Dalhousie University, Halifax, Nova Scotia.

Amanda Hudson is now at Health PEI; Shu-Ping Chen is now at Faculty of Rehabilitation Medicine at the University of Alberta.

This research was supported by funding from the Movember Foundation.

Correspondence concerning this article should be addressed to Laura Henderson, Department of Psychology, University of Calgary, 2500 University Dr. NW, Calgary, Alberta, T2N 2N4. Email: laura.henderson2@ucalgary.ca

The Caring Campus Toolkit is an integral part of the Caring Campus Project. The Toolkit can be accessed at https://doi.org/10.7870/ cjcmh-2018-018 
perceived administrative concern for mental health and substance abuse) and the relationships among these perceived campus environment variables and students' mental well-being, risk of harmful drinking, and their willingness to seek help for a substance use or mental health concern. A total of 1,885 first-year undergraduate university students including 938 females, 936 males and 11 "non-binary" participants, from three geographically diverse Canadian university sites, completed online surveys. The results demonstrated significant associations among the perceived campus environment variables and both mental health and alcohol misuse outcomes. It was also observed that whether a student lived in residence or off campus significantly affected which campus environment factors were most associated with their reported mental health and alcohol misuse. Additionally, willingness to help-seek was related with students' perceptions of campus culture. These patterns globally demonstrated the importance of campus culture for student mental health and alcohol use. Strengths and limitations of the study, as well as directions for future research on the relations of campus culture to mental health, substance use, and help-seeking are discussed.

Keywords: campus culture, mental health, substance abuse, undergraduates, emerging adults, help-seeking, alcohol misuse.

\section{RÉSUMÉ}

Bien que de nombreux facteurs de risque distinctifs aient été identifiés pour expliquer les problèmes de santé mentale et la consommation abusive d'alcool chez les étudiants, bien peu de recherches explorent dans quelle mesure des variables comme l'environnement d'étude peuvent contribuer à l'expérience vécue par les étudiants en lien avec ces problèmes. La présente étude porte sur divers facteurs environnementaux perçus (ex. : sentiment de valorisation et d'intégration, préoccupation du corps enseignant à l'égard des étudiants, sollicitude apparente de l'administration en ce qui concerne la santé mentale et les problèmes de toxicomanie des étudiants) et la relation qui existe entre ces variables propres à l'environnement du campus d'enseignement et le bien-être mental des étudiants, le risque de consommation excessive d'alcool et la volonté des étudiants de solliciter de l'aide s'ils éprouvent des problèmes de toxicomanie ou de santé mentale. Au total, quelque 1885 étudiants de première année du premier cycle universitaire ( 938 femmes, 936 hommes et 11 participants " non binaires ») issus de trois établissements d'enseignement canadiens géographiquement diversifiés ont répondu aux sondages en ligne. Les résultats ont démontré l'existence de liens significatifs entre les variables perçues de l'environnement du campus d'enseignement et leur résultante sur la santé mentale et la consommation abusive d'alcool. Il a également été constaté que le fait pour un étudiant de vivre en résidence ou à l'extérieur du campus affectait considérablement la nature des facteurs environnementaux du campus d'enseignement le plus souvent associés à sa santé mentale et à la situation qui lui est propre en ce qui concerne la consommation abusive d'alcool. De plus, la volonté de demander de l'aide était liée à la perception qu'avaient les étudiants de la culture du campus d'enseignement. Ces tendances ont démontré toute l'importance que revêt la culture du campus d'enseignement sur la santé mentale des étudiants et leur consommation d'alcool. Les points forts et les limites de l'étude, de même que les orientations futures de la recherche portant sur les relations entre la culture d'un campus d'enseignement et la santé mentale, la consommation de substances et la recherche d'aide sont évoqués dans le présent article.

Mots clés : culture du campus d'enseignement, santé mentale, toxicomanie, étudiants de premier cycle, adultes émergents, recherche d'aide, consommation abusive d'alcool. 
The American College Health Association survey conducted during the spring of 2016 with more than 40,000 Canadian post-secondary students from 41 post-secondary institutions reported that $64.5 \%$ of students indicated that they experienced overwhelming anxiety within the last year (American College Health Association, 2016). Further, more than $44 \%$ of students reported being so depressed within the last year that they struggled to function, and $13 \%$ of students seriously considered suicide within the past year. It is worth noting that the above rates had increased since the previous survey in 2013, possibly signifying a trend of increasing need. Approximately $25 \%$ of students reported that they had been diagnosed with, or treated for, a mental illness in the prior year (American College Health Association, 2016).

In addition to high rates of mental health concerns, Canadian post-secondary students reported significant rates of risky alcohol consumption. Seventy percent of students had consumed alcohol within the last 30 days and $35 \%$ reported that they had consumed five or more drinks on a single occasion within the last two weeks, which is the generally accepted definition of "binge drinking" or "heavy episodic drinking" (American College Health Association, 2016). Despite these high levels of mental health concerns and risky drinking practices among Canadian post-secondary students, fewer than 20 to $25 \%$ of Canadian young people who require mental health and addictions services seek professional help (Canadian Mental Health Association, 2016; Waddell, McEwan, Shepherd, Offord, \& Hua, 2005).

The consequences of poor mental health and heavy alcohol consumption are widespread, with poor academic performance often attributed to declining mental well-being (Keyes et al., 2012; Reavley \& Jorm, 2010). Within Canada, 39\% of students felt their academics had suffered due to stress, $28 \%$ due to anxiety, and $17 \%$ due to depression. Poor mental health is associated with declines in the motivation required to succeed in post-secondary education (Keyes et al., 2012). Students with a mental illness are more likely to drop out of university in the absence of support, and are more likely to increase their substance use and are less likely to engage in healthy eating, exercise, and sleep behaviours (Keyes et al. 2012; Reavley \& Jorm, 2010).

Rates of mental health problems and risky drinking behaviour, coupled with low rates of accessing professional services, may well be affected by the culture of Canadian campuses. Definitions of campus culture vary widely, but often incorporate elements of "persistent patterns of norms, values, practices, beliefs, and assumptions that shape the behavior of individuals and groups in a college or university and provide a frame of reference within which to interpret the meaning of events and actions on and off the campus" (Kuh \& Whitt, 1988, p. iv). Research on campus culture suggest that it is a critical factor in explaining the decisions and actions of students, and that campus culture can create circumstances of marginalization for students who may not feel like they are part of the dominant group (González, 2002).

A recent study by Chen, Romero, and Karver (2016) examined the relationships among students' perception of campus culture, personal stigma, and help seeking. The study found that students' views of mental health stigma and help seeking were related to their perceptions of their campus environment, and that those students who perceived their campus as more stigmatizing toward mental illness reported more personal stigma. These results make sense in light of research on barriers to seeking mental health treatment in university students, which emphasizes privacy concerns and perceived stigma (Hunt \& Eisenberg, 2010). Campus culture may also have positive impacts. For example, one study found that students who report that their campus environment was supportive and provided them with a sense of belonging experienced better mental health (Fink, 2014). 


\section{RISK FACTORS FOR MENTAL HEALTH PROBLEMS AND RISKY ALCOHOL CONSUMPTION}

Although many individual risk factors have been identified for student mental health problems and alcohol misuse, there is a relative paucity of research examining how variables such as the campus environment contribute to students' experiences of these problems. Below we summarize some of the known risk factors. As the current study examines campus culture as another potential risk factor, we also explore how Canadian undergraduate students' perceptions of their campus culture is associated with their mental health problems and alcohol misuse, as well as their willingness to seek help for these problems.

Post-secondary students exist in an environment that presents a variety of risk factors, which, when coupled with the fact that most students fall within the age at the highest risk for mental illness and substance use (i.e., 18-24 years), puts many students in a precarious situation (Zivin, Eisenberg, Gollust, \& Golberstein, 2009). University is a significant transition for many students, as it can include moving away from family and social supports, living alone or with new people for the first time, integration into a new environment, and the stress associated with juggling multiple responsibilities such as academic demands, a social life, and employment (Dyson \& Renk, 2006; Hunt \& Eisenberg, 2010; Keyes et al. 2012). Research has shown that college and university students are heavy alcohol users with a high prevalence of binge drinking (American College Health Association, 2016; Knight et al., 2002). Rates of alcohol use on university campuses was relatively stable between 1993 and 2005, but rates of excessive alcohol consumption increased over this same period, and binge drinking specifically had increased 38\% (National Center on Addiction and Substance Abuse, 2007; Wechsler et al., 2002). University students face adverse consequences in connection with their alcohol use, ranging from academic to legal problems. Heavy alcohol use is associated with a lower academic performance, more missed classes, the risk of academic withdrawal, and even self-injury (National Center for Addiction and Substance Abuse, 2007; Singleton, 2007).

While university life is associated with many known risk factors, a sense of belonging can offer many important benefits to students. Students who experience belonging have increased institutional commitment, earn higher grades, are more likely to complete their program, feel more satisfied, and report better mental health and well-being (Allen, Robbins, Casillas, \& Oh, 2008; Bowman, 2010; Kawachi \& Berkman, 2001). Students who report that they feel cared about and valued at their institution also report a stronger sense of positive campus community (Chen, 2004). Additionally, research has found that when a student reports feeling cared about, they also report better social and academic comfort on campus (Hoffman, Richmond, Morrow, \& Salomone, 2002). Peer acceptance and engaged professors appear to be critical factors that promote a sense of belonging. Additionally, feeling effective leads students to feel that they belong in the academic environment (Freeman, Anderman, \& Jenson, 2007).

College students drink more than their non-college attending peers, suggesting that there are factors related to the post-secondary environment that impact the frequency and amount of alcohol consumption (Blanco et al., 2008). However, while rates have remained relatively stable within institutions over time, the rates of binge drinking vary widely across post-secondary institutions (Wechsler et al., 2000). This observation

suggests that there may be components of the campus culture that are affecting student drinking rates. Some of the environmental features that have been shown to be significantly related to alcohol use on campuses 
include age of majority, price of alcoholic beverages, number of alcohol outlets, living in residence, and prevailing drinking rates on campus. When alcohol is advertised widely and promotions and sales are visibly marketed on or near campus, rates of binge drinking are higher (Chaloupka \& Wechsler, 1996; Kuo et al., 2003; Toomey, Lenk, \& Wagenaar, 2007). Additionally, the number of alcohol-serving establishments on campus and nearby positively correlates with greater student drinking (Kuo et al., 2003). Students who live in residence are more likely to binge drink than students who live off campus, and students who live with their families are least likely to binge drink (Chaloupka \& Wechsler, 1996; Cross, Zimmerman, \& O’Grady, 2009).

Depending on the type of extracurricular activity (e.g., involvement in fraternity/sorority, varsity athletics, volunteerism), involvement outside of academics can differentially affect students' sense of a positive campus community and the likelihood that they will engage in binge drinking. Despite the expectation that extracurricular involvement may increase a sense of belonging, most extracurricular activities do not have this effect, and membership in a fraternity or sorority has been shown to actually decrease a student's sense of community and belonging (Chen, 2004). Membership in a fraternity, sorority, or varsity athletics also increases the odds of regular and heavy alcohol use (Capone, Wood, Borsari, \& Laird, 2007; Nelson \& Wechsler, 2001; Wechsler, Dowdall, Davenport, \& Castillo, 1995). In contrast, students who are involved with their campus and the wider community through volunteerism are less likely to be binge drinkers (Borsari, Murphey, \& Barnett, 2007; Weitzman \& Chen 2005).

Mental illnesses and excessive alcohol use are strongly related in university students (National Center on Addiction and Substance Abuse, 2007). A study of 27,409 American students found that $81.7 \%$ of students who met the diagnostic criteria for depression or poor mental health consumed alcohol (Weitzman 2004). The same study found that male students who consumed alcohol and also had poor mental health were $11 \%$ more likely to get into trouble with the police than those who drank at equivalent rates but did not have any mental health challenges (Weitzman, 2004). Female students who struggled with mental health issues and consumed alcohol were significantly more likely to engage in self-harm behaviours (Weitzman, 2004). Another American study of 5,421 college students found a larger association between mental illness and alcohol abuse in females than for males (Lo, Monge, Howell, \& Cheng, 2013). It is common for students who struggle with poor mental health to attempt to cope through the use or abuse of alcohol (Lo, Monge, Howell, \& Cheng, 2013). This strategy can unfortunately create complications, as heavy alcohol use can result in additional mental health problems (Lo et al., 2013). Some research suggests that men are more likely than women to self-medicate with alcohol (Bolton, Cox, Clara, \& Sareen, 2006; Bolton, Robinson, \& Sareen, 2009).

The present research contributes to the literature that examines the relationships among campus culture, student mental health, and alcohol misuse. It also contributes to the limited study of Canadian post-secondary environments. More specifically, the study examined a series of perceived campus environment factors (e.g., feeling valued, feeling they fit in, believing faculty cared about them, perceived administrative concern for mental health and substance abuse) and the relationships among these perceived campus environment factors and students' mental well-being, risk of harmful drinking, and their willingness to seek help for a substance use or mental health concern. 


\section{METHOD}

\section{Participants}

Participants were 1,885 first-year undergraduate university students (938 females; 936 males; 11 identifying as "non-binary"), ranging from 16 to 25 years of age $(M=18.31$ years, $S D=1.09)$, recruited from three geographically diverse Canadian university sites: a Western Canadian site, a Central Canadian site, and an Eastern Canadian site. The majority of students lived in residence during the academic year (70\%), whereas others reported living with family (21\%), in an apartment with roommates (7\%), or in an apartment alone (2\%). Students represented a variety of degree programs, including Agriculture, Architecture, Arts, Business/Commerce, Computing, Education, Engineering/Applied Science, Fine Arts, Health Professions, Nursing, Physical Education/Kinesiology, and Science, with Arts (24\%) and Science (29\%) representing the two most common programs. A minority of students (9\%) were international students. Demographics were relatively similar across sites, with the exception that only male university students were recruited at one site (i.e., the Central Canadian site).

\section{Procedure}

First-year students were invited to participate in online surveys in the fall of 2014, which provided baseline data on a variety of measures related to student mental health and substance use. Ethical approval was granted by each institution's Research Ethics Board. Invitations to complete surveys were emailed to all first-year students at the Eastern Canadian site and to all first-year male students at the Central Canadian site. At both of these sites, weekly reminder emails were sent for three weeks until data collection was complete. The Western Canadian site emailed all students responding to recruitment advertisements and all first-year students living in residence. Although undergraduates of any year could participate in the Western site's survey, the analyses presented in the current paper were restricted to only first-year students' data. All three sites also used secondary recruitment strategies, including recruitment advertisements posted to social media, in university newsletters, and at various university venues. The response rate (i.e., proportion formally invited to complete the survey who did so) was 32\% for the Central and Eastern sites combined, which is comparable to survey response rates documented for other university surveys (American College Health Association, 2013; Canadian University Survey Consortium, 2013). The response rate at the Western site could not be determined, as broad social media and other invitations make it impossible to know how many distinct people were invited to complete the survey.

Participation was voluntary and participants were permitted to withdraw at any time. Willing participants provided informed consent by clicking "submit" to indicate that they agreed to the written terms and conditions. The survey took approximately 20 minutes to complete. Participants received compensation in the form of course credit or gift cards, or could donate the cash value of their compensation to mental health and substance harm reduction initiatives on their campus.

\section{Measures}

Campus culture. A variety of items were included in the surveys to evaluate students' perceptions of their campus culture, particularly in terms of sense of community, belongingness, and administration's 
concern for student mental health and substance use. To assess students' perceptions of these aspects of campus culture, students rated the items below on a five-point Likert scale, where 1 indicated "strongly disagree" and 5 indicated "strongly agree." Each item was included as a separate predictor in subsequent analyses.

1. I feel valued as a person on campus.

2. I fit well into the social life on campus.

3. I feel that faculty/staff care about me as a student.

4. The social atmosphere promotes alcohol use.

5. The prevention of alcohol-related problems are a high priority.

6. The administration is concerned about students' substance use.

7. The administration is concerned about students' mental health.

Alcohol misuse. The Alcohol Use Disorders Identification Test (AUDIT; Babor et al., 2001) was used to assess alcohol misuse. The AUDIT includes 10 items that assess hazardous alcohol use (three items), dependence symptoms (three items), and alcohol-related harm (four items). The AUDIT has strong psychometric properties (Babor et al., 2001), including internal consistency (alpha $=0.83$ ), one-week test-retest reliability ( $r=0.87$ ), and convergent validity (Reinert \& Allen, 2007; Rubin et al., 2006). Cronbach's alpha was .84 in the current study. Total summed scores were used to measure problematic alcohol use in the current study.

Mental well-being outcomes. The Kessler Psychological Distress Scale (the K10; Kessler et al., 2002) is a general measure of psychological distress (or, conversely, well-being). It includes 10 items that pertain to participants' current experiences of anxiety (e.g., "During the past 30 days, about how often did you feel so restless that you could not sit still?") and depression (e.g., "During the past 30 days, about how often did you feel so depressed that nothing could cheer you up?"). Participants rate each item on a five-point scale, ranging from 1 (none of the time) to 5 (all of the time). The K10 has shown good construct and concurrent validity in diverse populations, as well as high internal consistency (Bougie et al., 2016; Hides et al., 2007). Cronbach's alpha was .92 for the current study. The total summed score was included as the outcome in the current study. Higher scores represented greater psychological distress.

Help-seeking outcomes. To assess students' willingness to seek help for mental health or substance use concerns, students responded to the following item "I would be willing to tell someone in authority, such as a counselor or a professor, if I were experiencing mental health or substance use problems." Ratings were made on a five-point Likert scale, where 1 indicated "strongly disagree" and 5 indicated "strongly agree." This item was conceptualized as a type of self-care outcome that reflected students' readiness to request support or advice, when necessary.

\section{Data Analytic Plan}

Path analysis was employed to examine the associations among students' perceptions of campus culture and student mental health problems, alcohol misuse, and willingness to seek help. All models were fit using MPlus 7.11 (Muthén \& Muthén, 1998-2012) using full-information maximum likelihood estimation for missing data. In our hypothesized model, campus culture predictors measuring sense of belonging (i.e., "I feel valued," "I feel like I fit into the social life on campus," "I feel faculty/staff care about me") were regressed 
onto both mental health problems and alcohol misuse outcomes. Campus culture predictors pertaining to student substance use (i.e., "The social atmosphere promotes alcohol use," "Prevention of alcohol-related problems is a high priority," "The administration is concerned about students' substance use") were regressed onto alcohol misuse, whereas the campus culture predictor pertaining to mental health (i.e., "Administration is concerned about students' mental health") was regressed onto the mental health problems outcome. In a separate model, all campus culture predictors were regressed onto willingness to seek help.

As no prior research has investigated the above associations, we used modification indices (MI) to guide model re-specification. We used a cut-off of $M I=4.0$, as this is the value associated with reducing the model $\chi^{2}$ by a statistically significant amount at $p<.05$ if the identified path is re-specified. Paths that were not plausible or were not supported by theory or previous research were not added regardless of the value of the MIs. For both models, standard indices were used to assess model fit (i.e., RMSEA $\leq .05$ and CFI $\geq$ .95 indicate good fit and RMSEA $\leq .08$ and $\mathrm{CFI} \geq .90$ indicate adequate fit; Hu \& Bentler, 1999).

To account for the clustering of the data within the three data collection sites, two dummy variables representing collection site were included in the models (Muthén \& Muthén, 2016). Further, because of the variability in recruitment strategies across sites, sensitivity analysis was conducted to examine the results in a multiple-groups model. The potential moderating effects of gender and living arrangement (residence vs. non-residence) were also assessed using multiple-group models in which we compared changes in model fit resulting from imposing and releasing equality constraints on model parameters across groups (Bollen \&

Table 1

DescriptiveStatistics (Mean; SD) for all Predictor and Outcome Variables in Models

\begin{tabular}{|c|c|c|c|c|}
\hline Predictor and Outcome Variables & $\begin{array}{l}\text { Total Sample } \\
(\mathrm{N}=1,885)\end{array}$ & $\begin{array}{l}\text { Western } \\
\text { University } \\
(\mathrm{n}=436)\end{array}$ & $\begin{array}{l}\text { Central } \\
\text { University } \\
(\mathrm{n}=580)\end{array}$ & $\begin{array}{l}\text { Eastern } \\
\text { University } \\
(\mathrm{n}=869)\end{array}$ \\
\hline & Mean (SD) & Mean (SD) & Mean (SD) & Mean (SD) \\
\hline I feel valued on campus & $3.54(0.89)$ & $3.42(0.85)$ & $3.80(0.84)$ & $3.43(0.91)$ \\
\hline I fit well into the social life on campus & $3.50(1.00)$ & $3.31(0.99)$ & $3.76(0.97)$ & $3.43(1.00)$ \\
\hline I feel faculty care about me & $3.50(0.94)$ & $3.36(0.92)$ & $3.70(0.88)$ & $3.45(0.97)$ \\
\hline Admin concerned about mental health & $3.70(0.96)$ & $3.62(0.98)$ & $4.04(0.85)$ & $3.52(0.96)$ \\
\hline Admin concerned about substance use & $3.44(0.90)$ & $3.20(0.88)$ & $3.61(0.85)$ & $3.46(0.92)$ \\
\hline The atmosphere promotes alcohol & $3.70(0.96)$ & $3.50(0.95)$ & $3.96(1.03)$ & $3.64(0.99)$ \\
\hline Prevention of alcohol problems is a priority & $3.07(0.99)$ & $3.02(0.88)$ & $3.07(1.03)$ & $3.09(1.02)$ \\
\hline Mental Health, K10 & $22.02(8.07)$ & $22.72(8.14)$ & $20.47(7.53)$ & $22.70(8.24)$ \\
\hline Alcohol Misuse, AUDIT & $7.71(6.16)$ & $5.37(5.78)$ & $8.72(5.76)$ & $8.12(6.30)$ \\
\hline Willingness to seek help & $3.64(1.07)$ & $3.70(1.10)$ & $3.58(1.07)$ & $3.64(1.05)$ \\
\hline
\end{tabular}

Notes: All items use a 5-point scale, except the K10 and AUDIT which use 10-50 and 0-10 scales, respectively. 
Curran, 2006). Non-significant differences in model parameter estimates across groups indicate that there is no moderating effect of the parameter of interest.

\section{RESULTS}

\section{Campus Culture and Student Mental Health and Alcohol Use Outcomes}

Our hypothesized model was first tested using the total sample and provided a very good fit to the data, $\chi^{2}(4)=23.06, p<.001$, RMSEA $=.05(90 \% \mathrm{CI}=.03-.07), \mathrm{CFI}=.97$. Modification indices suggested adding two additional paths from "Administration is concerned about students' substance use" to mental health problems $(\mathrm{MI}=11.50)$ and from "The social atmosphere promotes alcohol use" to mental health problems

\section{Figure 1}

Associations Among Students' Perceptions of Campus Culture and Student Mental Health Problems and Substance Misuse

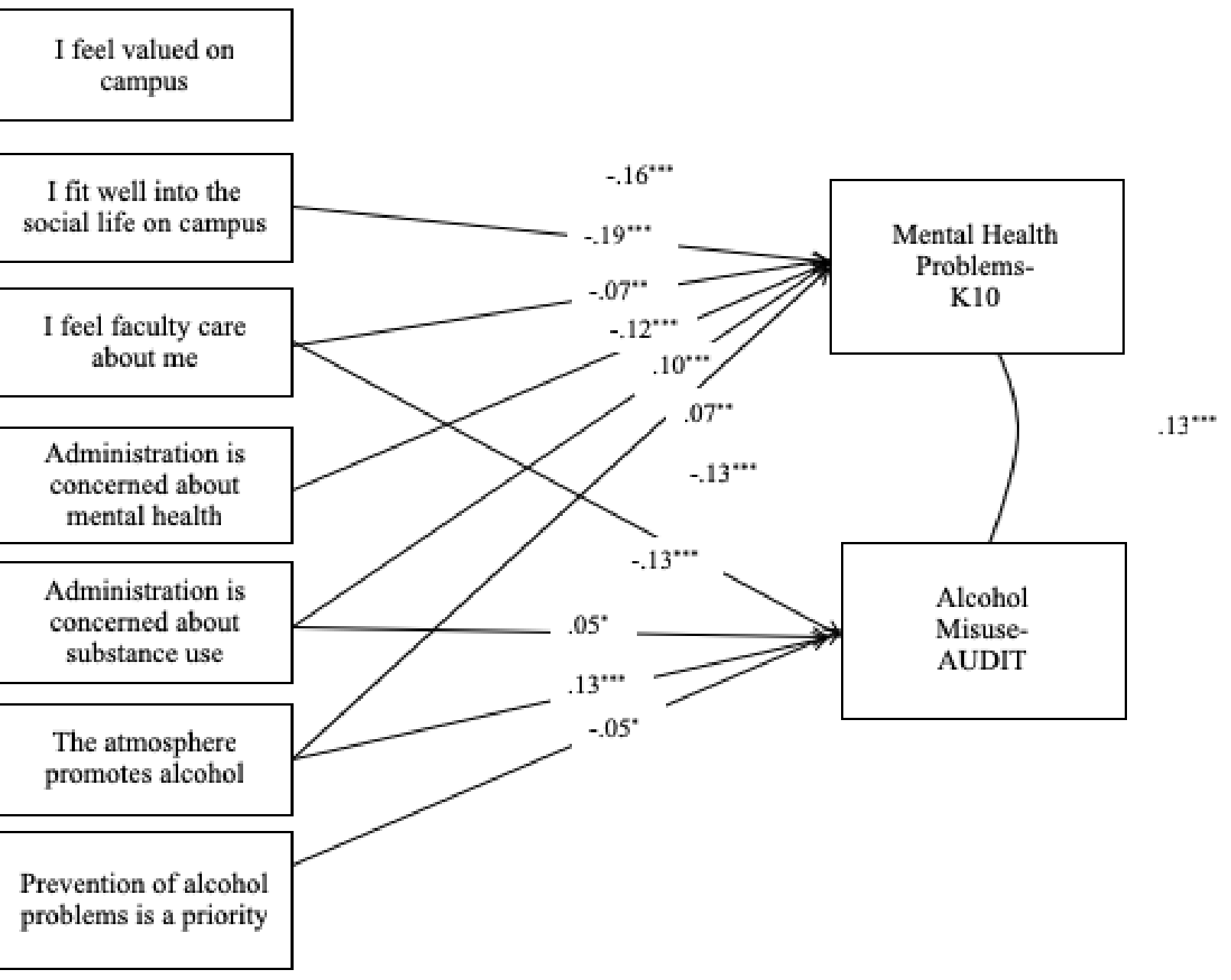

Note: $* \mathrm{p}<.05 ; * * \mathrm{p}<.01 ; * * * \mathrm{p}<.001$. 
$(\mathrm{MI}=8.23)$. Our re-specified model (see Figure 1) provided an excellent fit to the data, $\chi^{2}(2)=0.43, \mathrm{p}=.81$, RMSEA $=.00(90 \% \mathrm{CI}=.00-.03), \mathrm{CFI}=1.00$, and was significantly better than the hypothesized model $(\Delta \chi 2(2)=22.64, \mathrm{p}<.001)$.

Higher levels of feeling valued on campus and that faculty care about students were associated with significantly lower levels of both mental health problems and alcohol misuse. Believing that university administration is concerned about student mental health was also associated with lower mental health problems. Perceiving that the prevention of alcohol-related problems is a high priority on campus was associated with lower levels of alcohol misuse. In contrast, perceiving that the atmosphere on campus promotes alcohol use was associated with higher levels of alcohol misuse, and believing administration is concerned about students' substance use on campus was significantly associated with higher levels of both mental health problems and alcohol misuse among students. Feeling like you fit well into the social life on campus was significantly associated with lower levels of mental health problems but greater alcohol misuse.

In light of the variability in sampling procedures across universities, we conducted a sensitivity analysis using a multiple-groups model to test whether the structural parameters differed significantly across data collection sites. The chi-square difference test revealed that a model in which all paths were constrained fit significantly worse than a model in which the paths were free $\left(\Delta \chi^{2}(26)=46.97, p<.007\right)$. This result suggests significant differences in associations across the three sites. We systematically tested which paths could be constrained across sites by comparing changes in model fit that resulted from imposing and releasing cross-group equality constraints on specified paths. These analyses revealed that only a single path could not be constrained across sites: specifically, the association between feeling that you fit into the social life at university and problematic alcohol use was much stronger at the Central university $(B=.51, p<.001)$, compared to the other two universities combined $(B=.29, p<.001)$. Given that the observed association was significant and in the same direction at all three sites, we proceeded with a single combined model that controlled for site using dummy variables to facilitate the testing of moderation by gender and living situation.

\section{Associations Among Perceptions of Campus Culture and Student Mental Health and Alcohol Use, as a Function of Gender and Living Situation}

To test for moderation by gender, a model in which estimated paths were constrained across gender was compared to a model in which the estimated paths were allowed to vary across gender. The chi-square difference test revealed that a model in which parameters of interest were constrained across males and females fit as well as the model in which parameters were free $\left(\Delta \chi^{2}(13)=11.20, p=.59\right)$ suggesting that associations did not differ significantly by gender.

Similarly, to test for moderation by living arrangement, a model that constrained the paths between students living in residence and those not living in residence was compared to an unconstrained model. The difference test revealed that a model in which all paths were constrained fit significantly worse than a model in which the paths were free $\left(\Delta \chi^{2}(13)=54.94, p<.001\right)$, suggesting significant differences in the hypothesized associations between students who lived in residence compared to those who lived off campus. We systematically tested which paths could be constrained between residence and non-residence students by comparing changes in model fit resulting from imposing and releasing cross-group equality constraints 
on specified paths. Chi-square difference tests revealed that the associations between the predictors and mental health problems could be constrained across residence and non-residence students $\left(\Delta \chi^{2}(6)=58.95\right.$, $p<.18$ ). In contrast, three other paths between the campus culture predictors and alcohol misuse could not be constrained across residence and non-residence students. First, the positive association between feeling that you fit well into the social life on campus and alcohol misuse was significantly stronger for residence ( $B=.37, p<.001)$ compared to non-residence students $(B=.26, p<.001)$. Second, the positive association between perceiving that the atmosphere promotes alcohol use and higher levels of alcohol misuse was significant for residence students $(B=.17, p<.001)$ but non-significant for non-residence students $(B=.06$, $p=.14)$. Finally, the negative association between feeling that faculty care about you and alcohol misuse was significantly stronger for non-residence students $(B=-.28, p<.001)$ and only marginally significant for residence students $(B=-.06, p=.06)$. These first two differences suggest that problematic alcohol use is more strongly influenced by perceptions of campus drinking culture and the need to fit into that culture for students who live in residence compared to non-residence students. The last difference suggests that non-residence students experience a stronger protective effect on their alcohol misuse of feeling that faculty care, as compared to residence students.

\section{Perceptions of Campus Culture and Willingness to Seek Help}

Figure 2 presents the associations between the predictors and students' reported willingness to seek help for a mental health or substance use problem. All possible paths were estimated, and therefore fit statistics were not provided. Results showed that students reported a significantly greater willingness to seek help when reporting higher levels of feeling valued on campus and when they feel that campus administration is concerned about students' mental health. There was also a marginally significant $(p=.10)$ positive relationship between the perception that campus administration is concerned about substance use and the willingness to seek help. The perception that the social atmosphere on campus promotes alcohol use was significantly associated with a decreased willingness to seek help.

Similar to the previous model, we conducted a sensitivity analysis using a multiple-groups model to test whether the structural parameters differed significantly across data collection sites. The chi-square difference test revealed that a model in which parameters of interest were constrained across sites fit as well as the model in which parameters were free $\left(\Delta \chi^{2}(14)=17.35, p=.24\right)$ suggesting that observed associations did not differ significantly by site.

\section{Associations Between Perceptions of Campus Culture and Willingness to Seek Help as a Function of Gender and Living Situation}

To test for moderation by gender and living arrangement, models in which estimated paths were constrained across groups were compared to models in which the estimated paths were allowed to vary across groups. The chi-square difference tests suggested that there were no significant differences in the observed associations across gender $\left(\Delta \chi^{2}(7)=6.68, p=.46\right)$ or student living arrangement $\left(\Delta \chi^{2}(7)=13.23, p=.07\right)$. 
Figure 2

Associations Among Students' Perceptions of Campus Culture and Students' Willingness to Seek Help

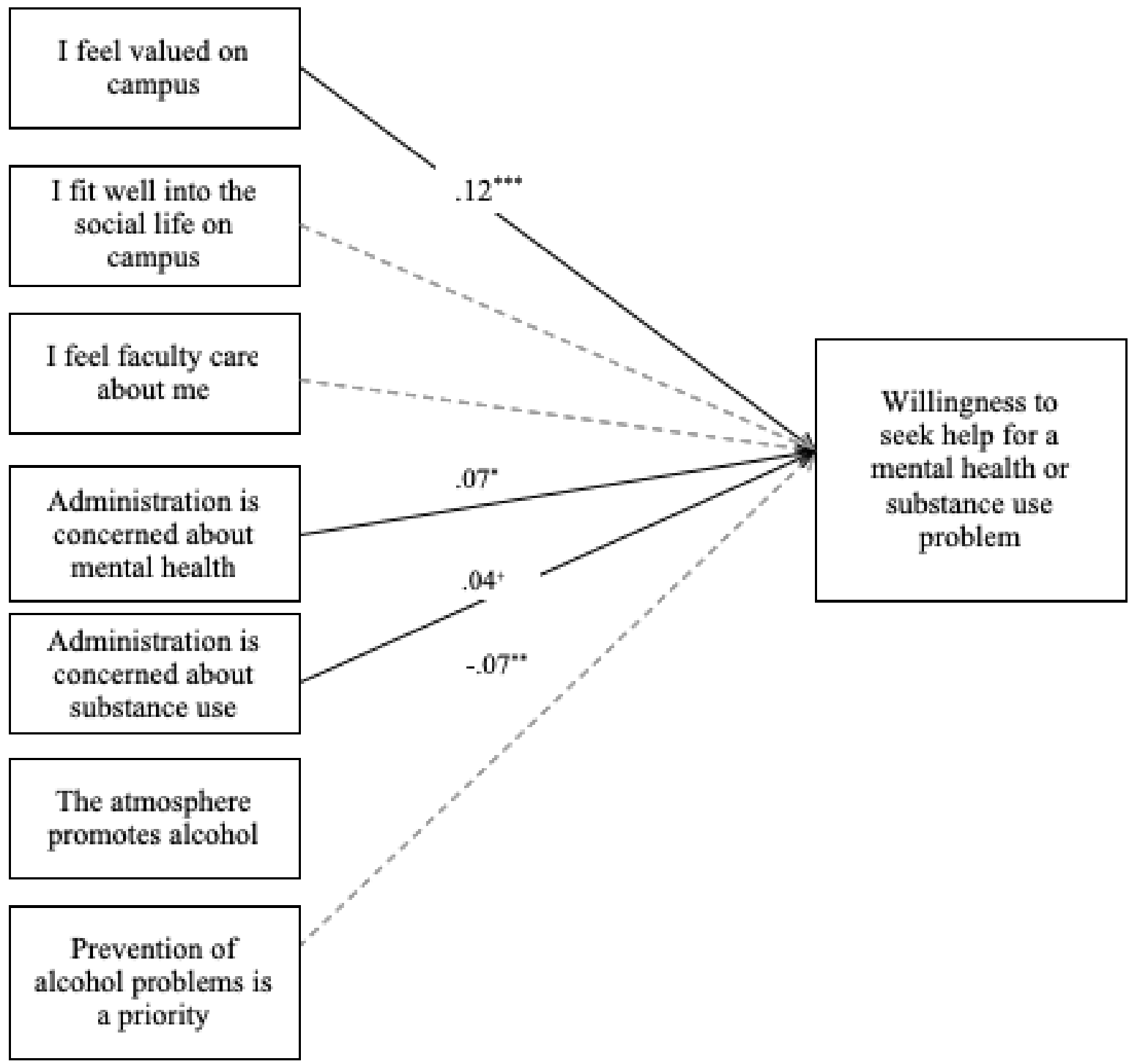

Note: $+\mathrm{p}=.10 ; * \mathrm{p}<.05 ; * * \mathrm{p}<.01 ; * * * \mathrm{p}<.001 ;$ dashed lines are not significant. 


\section{DISCUSSION}

This study evaluated how perceived campus environment is associated with student mental health and alcohol misuse, and students' willingness to seek help for these concerns. The results clearly demonstrated significant associations among the perceived campus environment variables and both mental health and alcohol misuse outcomes. It was also observed that whether a student lived in residence or off campus significantly affected which campus environment factors were most associated with their mental health and alcohol misuse. Additionally, willingness to help-seek was related with students' perception of campus culture.

One of the main results of the study was a positive association between campus culture items that evaluated students' sense of belonging and improved mental health and lower alcohol misuse. The observed relationship between feeling valued and fitting in and improved mental health has been well-established in the previous literature with students who report higher levels of belongingness also reporting better subjective well-being (Hoffman, Richmond, Morrow, \& Salomone, 2002; Kawachi \& Berkman, 2001). This sense of believing that they "fit" also has important implications for post-secondary completion, as research has further shown that students who do not complete their education more typically report low levels of believing they "ffit" with their school (Lambert, Zeman, Allen, \& Bussière, 2004). Other research shows that a sense of belonging can increase a student's commitment to the institution (Hausman, Scholfield, \& Woods, 2009). Our findings raise the interesting possibility that these effects of sense of belonging on academic outcomes may be mediated by effects on positive mental health.

Despite the result that the students who reported fitting into the social life on campus also reported better mental health, they also reported higher rates of alcohol misuse. This increased risky drinking behaviour is consistent with literature on social norms, which has demonstrated that students are more likely to consume alcohol if they perceive it to be an acceptable and normative behaviour on campus (McAlaney \& McMahon, 2007; Perkins, 2007). Additionally, research has found that students often report positive outcomes from drinking alcohol, such as meeting people and relaxing (Park, 2004). This perceived connection between alcohol use and positive outcomes may be further emphasized through the college environment, or the availability of alcohol on or near campus, both of which support higher rates of drinking. Additionally, research has shown that students report being more influenced by their positive alcohol-related experiences than by potential negative experiences (Park, 2004).

An important qualification to the connection between students feeling like they fit into campus life and a higher likelihood of alcohol misuse was that this connection was only significant for students living in residence. Similarly, the positive association between perceiving that the atmosphere promotes alcohol use and higher levels of alcohol misuse was significant only for students living in residence. These results align with other research that has found living in residence is a risk factor for heavy drinking (Wechsler et al., 2002; Wechsler, Dowdall, Davenport, \& Castillo, 1995). Residential living has also been shown to be connected to students' sense of belonging and connectedness (Kaya, 2004; Samura, 2016). It is possible that the closer relationships among residence students, and the associated desire to fit into the social life of residence, helps to explain why students who feel like they fit into campus life, and who perceive that the atmosphere promotes alcohol use, were more strongly related to alcohol misuse for those students living in residence. 
Another intriguing result was that only students who lived off campus demonstrated a positive relationship between their mental health and perceiving that faculty and staff cared about students. This relationship may have emerged because these students are less involved with the social life on campus than students living in residence, and so the sense of campus community for non-residence students is more heavily influenced by their interactions with faculty and staff. Other research has also found that professors have a significant role to play in whether or not a student feels like they belong on campus (Freeman, Anderman, \& Jenson, 2007). Our findings suggest that professors and other university staff can have an important role to play as the sense of belongingness that they help engender in students may have a protective effect on student alcohol misuse, particularly for students not living on campus.

Students reported lower levels of mental health problems when they perceived that the administration was concerned about mental health problems on campus; however, students reported higher levels of both mental health concerns and problematic alcohol use when they perceived that administration was concerned about substance use. One suggestion for this pattern of relationships may relate to differences in how campuses address mental health and substance use concerns. Recent mental health campaigns on campus tend to emphasize prevention, decreasing stigma, and peer support. This set of actions runs counter to substance misuse messaging and control strategies which are often disciplinary or punitive in nature, and which are often enhanced following a negative event associated with substances (i.e., reactionary rather than proactive). It is also possible that students who perceive that administration is concerned about substance misuse may be the students who have higher rates of substance misuse themselves, or who have been in trouble or sanctioned for their own use.

This study also examined the predictors of students' willingness to seek help for mental health and substance use concerns. Willingness to seek help was significantly predicted by whether a student felt valued and perceived that the administration was concerned about mental health on campus; a similar trend was observed for willingness to seek help to be predicted by perceptions that the administration was concerned about substance misuse on campus. This result aligns with previous studies that have similarly found that social supports increase the likelihood that someone will seek help (Rickwood \& Braithwaite, 1994) and extends this effect to perceived supports at the campus environment level. There is also evidence that improved knowledge about mental health services is associated with help seeking on postsecondary campuses (Eisenberg, Golberstein, \& Gollust, 2007). It seems likely that campuses that have engaged in awareness campaigns or that promote their mental health and substance misuse services may be perceived by students as being more concerned about these issues among the student body.

As with any study, this one has both strengths and limitations. Some of the strengths include the use of three Canadian universities to increase generalizability of findings, a large sample size to enhance the reliability of findings, and utilization of a common methodology across the three research sites to ensure standardization. The K10 (Kessler et al., 2002) and AUDIT (Babor et al., 2001) were two of the primary instruments and are well validated and have been used extensively in research with post-secondary student participants. Limitations of the study include sampling differences among the three research sites, an exclusive reliance on self-report variables and resulting shared method variance, and the use of a cross-sectional design which precludes conclusions about the directionality among variables associated with campus culture and student mental health and alcohol use. It is also important to note that this research was conducted in 
Canada, where the legal drinking age ranged from 18 to 19 across the three sites. As the legal age to purchase and consume alcohol varies in other countries and jurisdictions, it would be valuable to see whether these results generalize to campuses in other locations and cultural contexts. Longitudinal studies are required to disentangle the direction of the associations observed in the current study.

Future research could further explore institutional differences and the impact these have on individuals and their reported mental health and alcohol use. For example, all three of the universities included in the current study were comprehensive in nature (i.e., had a range of undergraduate, graduate and professional programs), and were relatively large. The use of colleges, technical schools and more undergraduate focused post-secondary institutions would be an interesting next step in research, and may yield important alternative results to the current study. This study also focused on individual level campus culture predictors (i.e., student perceptions of campus culture). An analysis of institution-level campus culture predictors (e.g., the presence or absence of different campus drinking policies, residence policies about alcohol consumption) would provide further understanding of the risk and protective factors associated with mental health problems and substance use in universities. This type of data could also assist student service providers to design their programs to optimally suit their institutions. Another direction for research includes a more in-depth examination of other factors that might affect whether or not students feel like they belong on campus. For example, programs that focus on inclusion of diverse students (e.g., based on religion, country of origin, sexual orientation) likely also promote a sense of support and belongingness, even though they are not directly related to mental health or substance misuse. An examination of broader inclusivity and support programs, and their effects on mental health and substance misuse could potentially be useful to create or modify campus programs to increase levels of wellness.

\section{REFERENCES}

Allen, J., Robbins, S. B., Casillas, A., \& Oh, I. S. (2008). Third-year college retention and transfer: Effects of academic performance, motivation, and social connectedness. Research in Higher Education, 49(7), 647-664.

American College Health Association. (2016). American College Health Association-National College health assessment II: Canadian reference groups data report. Spring 2016. Hanover, MD: American College Health Association.

American College Health Association. (2013). American College Health Association-National College health assessment II: Canadian reference groups data report. Spring 2013. Hanover, MD: American College Health Association.

Babor, T. F., Higgins-Biddle, J. C., Saunders, J. B., \& Monteiro, M. G. (2001). AUDIT: The alcohol use disorders identification test: Guidelines for use in primary care. Geneva: Department of Mental Health and Substance Dependence, World Health Organization.

Blanco, C., Okuda, M., Wright, C., Hasin, D. S., Grant, B. F., Liu, S. M., \& Olfson, M. (2008). Mental health of college students and their non-college-attending peers: Results from the National Epidemiologic Study on Alcohol and Related Conditions. Archives of General Psychiatry, 65(12), 1429-1437.

Bollen, K. A., \& Curran, P. J. (2006). Latent curve models: A structural equation perspective. Hoboken, NJ: Wiley-Interscience.

Bolton, J., Cox, B., Clara, I., \& Sareen, J. (2006). Use of alcohol and drugs to self-medicate anxiety disorders in a nationally representative sample. Journal of Nervous and Mental Disease, 194(11), 818-825.

Bolton, J. M., Robinson, J., \& Sareen, J. (2009). Self-medication of mood disorders with alcohol and drugs in the National Epidemiologic Survey on Alcohol and Related Conditions. Journal of Affective Disorders, 115(3), 367-375.

Borsari, B., Murphy, J., \& Barnett, N. P. (2007). Predictors of alcohol use during the first year of college: Implications for prevention. Journal of Addictive Behavior, 32(10), 2062-2086. 
Bougie, E., Arim, R. G., Kohen, D. E., \& Findlay, L. C. (2016). Validation of the 10-item Kessler psychological distress scale (K10) in the 2012 Aboriginal Peoples Survey. Health Reports, 27(1), 3-10.

Bowman, N. A. (2010). College diversity experiences and cognitive development: A meta-analysis. Review of Educational Research, 80(1), 4-33.

Canadian Mental Health Association. (2016). Fast facts about mental illness. Retrieved from http://www.cmha.ca/ media/fast-facts-about-mental-illness/

Canadian University Survey Consortium. (2013). 2013 First-year university student survey: Master report. Retrieved from: http://www.cusc-ccreu.ca/publications/2013_CUSC_FirstYear_master\%20report.pdf

Capone, C., Wood, M. D., Borsari, B., \& Laird, R. D. (2007). Fraternity and sorority involvement, social influences, and alcohol use among college students: A prospective examination. Psychology of Addictive Behaviors, 21(3), 316-327.

Chaloupka, F. J., \& Wechsler, H. (1996). Binge drinking in college: The impact of price, availability, and alcohol control policies. Contemporary Economic Policy, 4, 112-124.

Chen, J. I., Romero, G. D., \& Karver, M. S. (2016). The relationship of perceived campus culture to mental health help-seeking intentions. Journal of Counseling Psychology, 63(6), 677.

Cheng, D. X. (2004). Students' sense of campus community: What it means, and what to do about it. NASPA Journal, 41(2), 216-234.

Cross, J. E., Zimmerman, D., \& O’Grady, M. (2009). Residence hall room type and alcohol use among college students living on campus. Environment and Behavior, 41(4), 583-603.

Dyson, R., \& Renk, K. (2006). Freshmen adaptation to university life: Depressive symptoms, stress, and coping. Journal of Clinical Psychology, 62(10), 1231-1244.

Eisenberg, D., Golberstein, E., \& Gollust, S. E. (2007). Help-seeking and access to mental health care in a university student population. Medical Care, 45(7), 594-601.

Fink, J. E. (2014). Flourishing: Exploring predictors of mental health within the college environment. Journal of American College Health, 62(6), 380-388.

Freeman, T. M., Anderman, L. H., \& Jensen, J. M. (2007). Sense of belonging in college freshmen at the classroom and campus levels. Journal of Experimental Education, 75(3), 203-220.

González, K. P. (2002). Campus culture and the experiences of Chicano students in a predominantly White university. Urban Education, 37(2), 193-218.

Hausmann, L. R., Ye, F., Schofield, J. W., \& Woods, R. L. (2009). Sense of belonging and persistence in White and African American first-year students. Research in Higher Education, 50(7), 649-669.

Hides, L., Lubman, D. I., Devlin, H., Cotton, S., Aitken, C., Gibbie, T., \& Hellard, M. (2007). Reliability and validity of the Kessler 10 and Patient Health Questionnaire among injecting drug users. Australian \& New Zealand Journal of Psychiatry, 41(2), 166-168.

Hoffman, M., Richmond, J., Morrow, J., \& Salomone, K. (2002). Investigating “sense of belonging” in first-year college students. Journal of College Student Retention: Research, Theory \& Practice, 4(3), 227-256.

Hu, L., \& Bentler, P. (1999). Cutoff criteria for fit indexes in covariance structure analysis: Conventional criteria versus new alternatives. Structural Equation Modeling: A Multidisciplinary Journal, 6, 1-55.

Hunt, J., \& Eisenberg, D. (2010). Mental health problems and help-seeking behavior among college students. Journal of Adolescent Health, 46(1), 3-10.

Kawachi, I., \& Berkman, L. F. (2001). Social ties and mental health. Journal of Urban Health, 78(3), $458-467$.

Kaya, N. (2004). Residence hall climate: Predicting first-year students' adjustments to college. Journal of the First-Year Experience and Students in Transition, 16(1), 101-118.

Kessler, R. C., Andrews, G., Colpe, L. J., Hiripi, E., Mroczek, D. K., Normand, Sl.-L. T., Walters, E. E., \& Zaslavsky, A. M. (2002). Short screening scales to monitor population prevalences and trends in non-specific psychological distress. Psychological Medicine, 32, 959-976.

Keyes, C. L., Eisenberg, D., Perry, G. S., Dube, S. R., Kroenke, K., \& Dhingra, S. S. (2012). The relationship of level of positive mental health with current mental disorders in predicting suicidal behavior and academic impairment in college students. Journal of American College Health, 60(2), 126-133.

Knight, J. R., Wechsler, H., Kuo, M., Seibring, M., Weitzman, E. R., \& Schuckit, M. A. (2002). Alcohol abuse and dependence among U.S. college students. Journal of Studies on Alcohol, 63(3), 263-270. 
Kuh, G. D., \& Whitt, E. J. (1988). The Invisible Tapestry. Culture in American Colleges and Universities. ASHE-ERIC Higher Education, Report No. 1, 1988. Association for the Study of Higher Education, Dept. E, One Dupont Circle, Suite 630, Washington, DC 20036-1183.

Kuo, M., Wechsler, H., Greenberg, P., \& Lee, H. (2003). The marketing of alcohol to college students: The role of low prices and special promotions. American Journal of Preventative Medicine, 25(3), 204-211.

Lambert, M., Zeman, K., Allen, M., \& Bussière, P. (2004). Who pursues postsecondary education, who leaves and why: Results from the Youth in Transition Survey. Ottawa: Statistics Canada and Human Resources and Skills Development Canada.

Lo, C. C., Monge, A. N., Howell, R. J., \& Cheng, T. C. (2013). The role of mental illness in alcohol abuse and prescription drug misuse: Gender-specific analysis of college students. Journal of Psychoactive Drugs, 45(1), 39-47.

McAlaney, J., \& McMahon, J. (2007). Normative beliefs, misperceptions, and heavy episodic drinking in a British student sample. Journal of Studies on Alcohol and Drugs, 68(3), 385-392.

Muthén, L. K. (2016). Mplus user's guide. Los Angeles, CA: Muthén \& Muthén 1998-2010.

National Center on Addiction and Substance Abuse (CASA), at Columbia University, \& Califano, J. A. (2007). Wasting the best and the brightest: Substance abuse at America's colleges and universities. New York: CASA.

Nelson, T. F., \& Wechsler, H. (2001). Alcohol and college athletes. Medicine \& Science in Sports \& Exercise, 33(1), 43-47.

Park, C. L. (2004). Positive and negative consequences of alcohol consumption in college student. Journal of Addictive Behaviors, 29, 311-321.

Perkins, H. W. (2007). Misperceptions of peer drinking norms in Canada: Another look at the "reign of error" and its consequences among college students. Addictive Behaviors, 32(11), 2645-2656.

Reavley, N. \& Jorm, A. F. (2010). Prevention and early intervention to improve mental health in higher education to students: A review. Early Interventions in Psychiatry, 4, 132-142.

Reinert, D. F., \& Allen, J. P. (2007). The Alcohol Use Disorders Identification Test: An update of research findings. Alcoholism: Clinical and Experimental Research, 31, 185-199.

Rickwood, D. J., \& Braithwaite, V. A. (1994). Social-psychological factors affecting help-seeking for emotional problems. Social Science and Medicine, 39(4), 563-572.

Rubin, A., Migneault, J. P., Marks, L., Goldstein, E., Ludena, K., \& Friedman, R. H. (2006). Automated telephone screening for problem drinking. Journal of Studies on Alcohol, 67(3), 454-457.

Samura, M. (2016). How can residence hall spaces facilitate student belonging?: Examining students' experiences to inform campus planning and programs. Planning for Higher Education, 44(4), 90-101.

Singleton, R. A. (2007). Collegiate alcohol consumption and academic performance. Journal of Studies on Alcohol and Drugs, 68(4), 548-555.

Toomey, T. L., Lenk, K. M., \& Wagenaar, A. C. (2007). Environmental policies to reduce college drinking: An update of research findings. Journal of Studies on Alcohol and Drugs, 68, 208-219.

Waddell, C., McEwan, K., Shepherd, C. A., Offord, D. R., \& Hua, J. M. (2005). A public health strategy to improve the mental health of Canadian children. Canadian Journal of Psychiatry, 50(4), 226-233.

Wechsler, H., Dowdall, G. W., Davenport, A., \& Castillo, S. (1995). Correlates of college student binge drinking. American Journal of Public Health, 85(7), 921-926.

Wechsler, H., Kuo, M., Lee, H., \& Dowdall, G. W. (2000). Environmental correlates of underage alcohol use and related problems of college students. American Journal of Preventative Medicine, 19(1), 24-29.

Wechsler, H., Lee, J. E., Kuo, M., Seibring, M., Nelson, T. F., \& Lee, H. (2002). Trends in college binge drinking during a period of increased prevention efforts: Findings from 4 Harvard School of Public Health College Alcohol Study surveys: 1993-2001. Journal of American College Health, 50(5), 203-217.

Weitzman, E. R. (2004). Poor mental health, depression, and associations with alcohol consumption, harm, and abuse in a national sample of young adults in college. Journal of Nervous and Mental Disease, 192(4), 269-277.

Weitzman, E. R., \& Chen, Y. Y. (2005). Risk modifying effect of social capital on measures of heavy alcohol consumption, alcohol abuse, harms, and secondhand effects: National survey findings. Journal of Epidemiology and Community Health, 59, 303-309.

Zivin, K., Eisenberg, D., Gollust, S. E., \& Golberstein E. (2009). Persistence of mental health problems and needs in a college student population. Journal of Affective Disorders, 117, 180-185. 